\title{
DIE PSIGOLOGIE VAN DIE BEJAARDE
}

\section{deur}

Dr. S. J. PRINS

\section{A. Inleiding}

Gilhuis (1956, p. 91) sê : „De oude dag is niet zonder meer een verlengstuk van de volwassen leeftijd; de grijsaard is in vele opzichten een ander mens dan tevoren; hoe ook de grondlijnen van persoon en karakter gelijk gebleven zijn. Zoals het kind heden niet meer beschouwd wordt als een volwassen mens in het klein, maar als een menselijk wezen met eigen aard en struktuur, zo is de bejaarde niet een volwassen mens, in het oud' maar een mens met eigen karakterstructuur en persoonlijkheid, met speciale vragen en problemen, in velerlei opzichten verschillend van de mons die hij was op middelbare leeftyd. $\mathrm{Hij}$ vraagt dus een bijzondere benadering en behandeling".

In die lig hiervan is dit noodsaaklik dat diegene wat daagliks met bejaardes te doen het, soos oue tehuis-personele en predikante, goed op hoogte sal wees met die sielkunde van die bejaarde.

\section{B. Aanvang van bejaardheid}

Oor die algemeen laat navorsers op hierdie gebied die ouderdom 'n aanvang neem na die oorgangsperiode in die vyftigerjare. Van werklike ouderdom word vanaf die sewentigste jaar gepraat. Kok (1958, p. 21), en Young (1952, p. 571) is egter die mening toegedaan dat die kronologiese kriterium vir die aanvang van die ouderdom nie voldoende en ook nie steekhoudend is nie, want „De leeftijdsbepaling geschiedt in een tijdsnorm, de ouderdom word bepaald specifieke fysiologische kenmerken, en is dus in wezen een functiebepaling". Dit is meer juis om te aanvaar dat die ouderdom begin wanneer daar 'n groter liggaamlike afbreking as opbouing plaasvind. Dit gebeur nie by almal op dieselfde ouderdom nie.

Hoewel die ouderdom 'n spesifieke fisiologiese patroon vertoon, kan die psigologiese reaksies nie losgemaak word van die fisiologiese gesteldheid nie. Derhalwe is dit gerade om die fisiese sowel as psigiese aspekte van die ouderdom te ken ten einde die sielkunde van die bejaarde goed te verstaan. 


\section{DIE FISIOLOGIESE ASPEKTE VAN BEJAARDHEID}

Die fisiologiese veranderinge tydens die ouderdom word onder andere deur die volgende gekenmerk :

\section{(a) Atrofie of Uitdroging van Liggaamsdele en Selle}

Liggaamsrondinge word kleiner, platter en hol. Die wange, oogholtes en lippe val bv. in. Die weefsels kwyn weg en as gevolg daarvan word die liggaamsorgane kleiner en die gestalte verkrom.

\section{(b) Afname in Vitaliteit of Lewenslustigheid}

Die bejaarde herstel nie so maklik nie, en herwin ook nie weer gou en ten volle verlore liggaamskragte nie. Afgebreekte en beskadigde selle en elemente word weliswaar weer vervang en herstel tot by die dood, maar die lewenskrag van die nuwe elemente verminder. Reserwe kragte val weg. Die verbrandingsproses verminder en so ook die behoefte aan voedsel.

(c) Afname in Plastisiteit en Aanpassingsvermoë van die Liggaam

Hierdeur word die liggaam stram en minder beweeglik, asook minder aanpasbaar by die verskillende uitwendige situasies. Die verminderde plastisiteit werk ouderdomsblindheid en doofheid in die hand. Dit is gebreke waarby die bejaarde moeilik aanpas omdat dit in die ouderdom nie moontlik is om deur middel van dic oor-ontwikkeling van 'n sintuig te kompenseer vir die verlies van 'n ander nie. In die jong dae vind so 'n aanpassing makliker plaas. Die verswakte plastisiteit van die huid bemoeilik ook die bejaarde se aanpassing by wisselende temperature.

\section{PSIGOLOGIESE ASPEKTE VAN BEJAARDHEID}

Die psigologiese reaksies, of die gedrag van die mens berus grotendeels op sy (1) Kenlewe, (2) Gevoelslewe en (3) Wilslewe. Uit die aard van die saak sal dit weer beīnvloed word deur die fisiologiese gesteldheid van die persoon. Die kenmerkende fisiologiese aspekte van die ouderdom sal dus tot 'n baie groot mate die psigiese lewe van die oumens beînvloed en bepaal.

\section{DIE KENLEWE}

In die kenlewe is veral van belang die (a) Waarnemingsfunksie (b) die Geheuefunksie, en die (c) Verbindingsfunksie. 
Om waar te neem is om bewus te word van sintuiglike prikkels en so die omringende omgewing in al sy besonderhede te ken. Die bejaarde se sintuie het egter oud geword en dit is minder elasties. Gevolglik neem hy minder intens waar. Omdat die bejaarde egter nie meer in die volle stroom van die lewe staan nie, verflou sy belangstelling dienooreenkomstig, as gevolg waarvan hy ook minder dinge waarneem.

Die feit dat die waarnemingsfunksie 'n verandering ondergaan, bring ook 'n wysiging mee in die bejaarde se tydsin.

Die tyd verloop vir hom vinniger. Hierdie bepaalde tydsbelewing is baie belangrik vir die psigiese lewe van die oudag. Hieruit word verder afgelei dat, anders as wat die gangbare gedagte is, verveling nie altyd die oudag kenmerk nie. Sy tydsin word egter ook bepaal en gemotiveer deur bepaalde verlangens en ideale wat daar by hom lewe. As die oumens begin uitsien of verlang na die einde, sal die tyd nie meer te vinnig verbygaan nie, maar te stadig. Die ongelowige bejaarde wat die dood sien as 'n ewige afsluiting, as die finale einde van alles, verlang dan na die einde wat die dood meebring. Die gelowige aan die ander kant, verlang na die nuwe begin met Christus wat begin aan die anderkant van die graf. Die verwagting van die einde of die nuwe begin. bring 'n nuwe spanning mee wat die tydsbelewing ook verander.

'n Ander aspek van die bejaarde se tydsin is sy s.g. retrospektiewe instelling. Dit is sy neiging om terug te kyk en by sy herinneringe te gaan lewe. Hy is nie meer self by die sake van die dag betrokke nie. Hy staan eenkant, langs die lewensstroom en toekyk, wat geensins bevorderlik is vir sy daadwerklike belangstelling in die hede nie. Daarby is 'n sosiale faktor werksaam. Die rol wat hy nou speel in die samelewing is soveel kleiner as dié in die bloei van sy lewe. Dit veroorsaak 'n minderwaardigheidsgevoel en spoor hom aan tot kompensasie. Laasgenoemde word bereik deur aan die verlede vas te klem toe hy nog 'n belangriker status beklee het en 'n groter rol gespeel het.

Waar die verlede 'n steunpilaar en anker vir die grysaard se wankelende selfgevoel word, is die neiging dikwels daar om die verlede 'n ander kleur te gee. Alleen die mooi en goeie dinge uit die verlede word onthou en oorvertel, geaksentueer en geidealiseer. Soms word daar ook baie gefantaseer. 


\section{(b) Die Geheuefunksie}

Aangesien die belangstelling in die sake van die hede taan a.g.v. redes wat reeds genoem is, word die huidige gebeure ook nie ingeskerp en onthou nie. Dinge van kort gelede het nêrens in die geheue vasgesteek nie, maar gebeure van vanmelewe staan die oue van dae nog helder voor die gees.

Tot die kenlewe behoort egter nie net die waarnemende of ontvangende funksie, en die geheue- of bewarende funksie nie, maar ook die

\section{(c) Verbindende Funksie}

Hieronder word verstaan voorstellings, begrippe, assosiasies en denke.

(i) Voorstellings. Die belangrikste verskynsel hier is drome. Ofskoon die bejaarde 'n verswakte konsentrasievermoë na buite het, is dit besonder skerp na binne gerig, d.w.s. op sy eie innerlike lewe. Gevolglik onthou die ou mens sy drome en dink gedurende die dag voortdurend daaroor na. Dikwels word daar gedroom oor die eie afsterwe en begrafnis. Op grond hiervan is Gilhuis daarvan oortuig dat drome 'n belangrike punt in oumens-problematiek is.

Naas die drome is daar die dagdrome wat 'n bekende verskynsel by bejaardes is. Gewoonlik gaan die dagdrome oor die eie persoon in 'n vorige situasie, d.w.s. toe die bejaarde nog jonk en sterk was. Gevolglik is ook die dagdrome kompensasiemotiewe vir minderwaardigheidsgevoelens wat voortspruit uit die verlore rol en sosiale status van weleer. Dagdrome in 'n oordrewe mate kan natuurlik baie afmattend word vir die oumens.

\section{(ii) Assosiasies}

'n Assosiasie is die wyse waarop idees aaneen geskakel word op grond van kontras, ooreenkoms en samehang in ruimte en tyd. Die aanwesigheid van een idee roep dan die ander op d.m.v. die assosiasie. (Harringman (1947, p. 34).

By die oue van dae is die assosiasies uit die aard van die saak baie subjektief. Dit hou voortdurend verband met die gevoelsbelewing van die vroeëre, d.w.s. jonger situasie en daarom is dit uit pas met die huidige toestande. Vandaar dat die oumens gedurig die huidige omstandighede, gewoontes en gebruike kritiseer. 


\section{(iii) Denke}

Die denke van die grysaard is baie gerem en sy redenasies is uit hoofde hiervan wydlopig, stokkerig, vaag en onsamehangend. Versinsels en fantastiese denke is dikwels nie seldsaam nie. Nuwe gedagtes is egter uiters seldsaam en die wat daar is, sentreer grotendeels om die self, eie liggaam en eie aktiwiteite. Dit is moontlik dat dit selfsug kan bevorder.

\section{DIE GEVOELSLEWE}

Die gevoelslewe is baie belangrik vir die menslike persoonlikheid. Dit beïnvloed sowel sy denke as sy wil. „Hier niet het minst liggen daarom de oorzaken waarom de oude mens in zoveel opzichten een ander geworden is dan tevoren". (Gilhuis, a.w., p. 78).

Daar is die volgende gevoelens :

\section{(a) Liggaamlike Gevoelens}

Tesame met die belangstellingsverflouing takel ook die liggaam af. Om verstaanbare redes word die aandag nou meer gefikseer op die veranderende liggaamlike verskynsels. Bejaardes merk dan meer as jeugdiges hulle liggaamlike funksies op. Die maag word gevoel, die hart vasgehou, die bene voortgesleep ens.

\section{(b) Vitale Gevoelens}

Dit is gevoelens van welsyn, frisheid, lewenslustigheid, lusteloosheid, matheid ens. Dit vorm die grondslag vir die gemoedslewe en stemmingtoestande, en geniet groot belangstelling by bejaardes. Aangename en lewenslustige gevoelens word tydig en ontydig bekend gemaak, terwyl jonger mense nooit daaroor praat nie, omdat dit vir hulle vanselfsprekend is. Vir die bejaarde is dit belangrik omdat hy bewus is van sy naderende dood. Onaangename en sieklike gevoelens baar vir hom sorg en angs omdat dit vir hom die dood meer werklik laat word. Aangename gevoelens laat die werklikheid van die dood tydelik wyk en versterk sy lewensliefde.

\section{(c) Stemmings}

Die liggaamlike aftakeling en die vereensaming van die bejaarde a.g.v. sy veranderde sosiale status, het 'n geweldige invloed op die stemmings van die oudag. Terneergedrukte stemmings word veroorsaak deur gefrustreerde psigiese gevoelens sowel as deur minderwaardigheidskomplekse. Ook 
die omgewing speel ' $n$ rol in die verwekking van die besondere stemming. Gilhuis (a.w., p. 69) is van mening dat „Ouderen die voortdurend samen zijn, in een rusthuis bv. zullen daarom spoediger in mineur-stemmingen vervallen, dan degenen die verkeren onder levenskrachtige mensen in een ,gehobene stemming' ".

'n Kenmerkende stemming van die bejaarde is angs. Die bejaarde is op homself gewerp. Onder die blik na die self kom hy duidelik onder die indruk van sy nietigheid en sy voortgang na die einde. Met nog net 'n kort stukkie van die toegemete tyd voor hom, verdwyn ast'ware sy toekoms. In 'n hede wat gevul is met al die ouderdomsgebreke en onvermoëns, sonder 'n toekoms waarin 'n doel en opdrag roep, groei die sinloosheid van die bestaan al groter. In hierdie "niks" met slegs die dood as sekerheid, is die oumens geneig om al sy misdrywe en skuld van die jare in herinnering te roep. Langs hierdie berg van skuld word die angs dan monsteragtig groot in hom. Die bejaarde het tyd om te mediteer. Daarom is die lewensaand so 'n vrugbare tyd vir die ontstaan van stemminge.

Dit gebeur egter ook dat bejaardes stemmingloos word. Dit is ' $n$ toestand van gevoelloosheid wat baie probleme meebring omdat daar in so 'n toestand geen kontak met hom gemaak kan word nie.

\section{(d) Psigiesee Gevoelens}

Dit is gevoelens van smart, rou, leed, droefheid, blyheid, vreugde, simpatie ens. Onderskeid kan gemaak word tussen persoonlike en sosiale gevoelens.

(i) Persoonlike of Individualiteitsgevoelens. Dit omvat gevoelens van selfgelding, trots, hoogmoed en minderwaardigheid. Dit kom tot openbaring in gevoelens van mag en eiewaarde, of omgekeerd in gevoelens van onmag en waardeloosheid.

Die ouderdom bring met sig mee ook 'n verswakking van die psigiese kontrole. 'n Persoon word bv. maklik ontroer en trane vloei dikwels vrylik. Hierdie onvermoë om die eie innerlike te beheer tesame met die verskuiwing van die eertydse posisie, bring dikwels minderwaardigheidsgevoelens mee met die gevolglike frustrasie van die gevoelens van mag en eiewaarde.

Kompensasie word soms gesoek en ook verkry uit die 
herbelewing van die verlede. Dit verskaf egter nooit ten volle bevrediging nie aangesien herinneringe anders is as die oorspronklike ervarings. Dit verloor die oorspronklike intensiteit, of dit word op onwaaragtige wyse oordryf. Dit veroorsaak 'n oordrewe egoïsme by swak geintegreerde bejaardes.

Gevoelens van waarde is eties van aard en word tot 'n groot mate bepaal deur die omgewing (publieke opinie) wet en gewete. Godsdienstige oumense het dikwens te kampe met gevoelens van waardeloosheid voor God.

Dit gebeur in die oudag dat losbandige bejaardes verander tot vromes en vromes tot losbandiges. Laasgenoemdes sê wat het die godsdienstigheid van die verlede tog gehelp?

Ander weer word utiliste. Die ouderdom kan derhalwe beskou word as 'n gevaarlike tydperk.

\section{(ii) Sosiale Gevoelens}

Hieronder val gevoelens soos medelye, afguns, simpatie, barmhartigheid, haat, liefde, ens. Die sosiale gevoelens van die bejaarde sentreer oor die algemeen om tydgenote, terwyl dit t.o.v. die hedendaagse gemeenskap taan. Vandaar die s.g. "generasie-stryd" wat daar by talryke oumense is. Hulle het naamlik geen goeie woord vir, en geen medelye met die jonger geslag nie.

Dit gebeur dat „De ik-gevoelens krijgen de overhand op de sociale. De instelling word egocentrischer. Hieruit kunnen antipatetische gevoelens ontstaan, wrok, afgunst, haat. Daarmee wreekt men zich op het leven dat hen uitgestoten heeft" (Gilhuis, a.w. p. 73). Die sosiale gevoelens is minder diep as voorheen - die oumens is minder emosioneel t.o.v. liefde, medelye en haat. Dit bring mee dat die ouderdom dikwels die ware gevoelens van die persoon blootlê wat tydens sy jongjare altyd sorgvuldig verberg was. Die verswakte psigiese kontrole laat die masker voor die ware self val en dan word dit dikwels duidelik dat die persoon wat altyd sulke verhewe sosiale ideale gehad het, dit eintlik maar gedoen het om selfsugtige redes.

Hier kom ook die verskynsel van heimwee ter sprake wat volgens Carp 'n gevoel is ,van verlatenheid, gepaardgaande met een onbestemde drang naar gezin, familie, huis, geboortegrond". Aangehaal deur Gilhuis, a.w., p. 74). Rümke meen egter dat die omgewing baie belangrik is in die geval van heimwee. Dit kom veral voor by oumense as hulle 
hulle omgewing gedwonge moet verlaat. Dierbares, vriende en bekendes word agtergelaat en 'n nuwe omgewing word betrek. Hier is dit alles anders. Gedagtig aan die verswakte vermoë tot aanpassing, bring dit die persoon dan in die grootste eensaamheid.

\section{(e) Hoër Geestelike Gevoelens}

Dit omvat religieuse-, etiese- en astetiese gevoelens.

\section{(i) Religieuse Gevoelens}

In die ouderdom vind die religieuse gevoelens 'n versterking. By baie egter is hierdie gevoelens labiel. Nou is die grysaard baie terneergedruk deur gevoelens van verlorendheid en twyfel, netnou is hy weer opgeruimd en vreugdevol as gevolg van gevoelens van geloof en gemeenskap met God, want Gilhuis, (A.w. p. 75) sê : „Bij practisch alle gelovige ouderen prevaleert in de oudere jaren de persoonlijke verhouding tot God. Geworpen op zichzelf, werpt de mens zich op God, de oerbron van zijn bestaan. Dit is een rijke bron voor zaligheid en vreëgevoelens". Bepalend vir die religieuse gevoelens is die instelling van die bejaarde op die dood en op dit wat daarop volg. Nou is daar 'n sterk neiging om weer kwaai gebuk te gaan onder skuldgevoelens wat in die jeug reeds verskyn het, maar daarna tydens die stryd om die bestaan, weer vergeet is.

\section{(ii) Etiese Gevoelens}

Dit is gevoelens wat verband hou met die hoëre lewensnorme en waar daar onderskei moet word tussen die goeie en die kwaaie. Die verantwoordelikheidsgevoel val gewoonlik in die ouderdom. Vandaar die bederwery van kleinkinders. Die dinge wat vroeër verkeerd gelyk het en as nadelig vir die opvoeding beskou is, word in die ouderdom as minder verkeerd aanvaar. Die etiese gevoelens van die ouderdom berus natuurlik tot 'n groot mate op die etiese beginsels wat gedurende die hele lewe van die persoon by hom werksaam was.

\section{(iii) Estetiese Gevoelens}

Dit hou verband met die waardering van die mooie en die skone. Die bejaarde kry nou meer oog vir die skoonheid van die natuur. Die wêreld is vir hom nou mooier omdat dit haas tyd word dat hy dit moet verlaat. Wat kunswaardering betref het die bejaarde meer waardering vir die kunsprodukte uit sy eie tyd. 


\section{DIE WILSLEWE}

Die vroeë wilslewe van die grysaard bepaal die aard daarvan in die oudag. Die veranderde wilslewe van die oudag kan in die volgende hooftrekke geskets word:

Aangesien die oumens geneig is om meer terug te kyk as vorentoe, verswak dit sy wil, want Waterink sê : „Het gevoel plaatst ons in het nu, in het heden; de wil doet ons altijd grijpen naar het straks, naar de toekomst".

Die dryfkrag agter 'n wilsdaad is 'n doelstelling, en die sterkte van die dryfkrag of motief hang af van die waardeoordeel wat aan die doelstelling tèn grondslag lê.. Dog omdat die oumens baie geneig is om dinge relatief te sien en dus nie meer baie entoesiasties oor 'n saak kan raak nie, is sy wilslewe baie minder intens. As gevolg daarvan dat die horison van sy toekoms nie meer ver en wyd is nie, en hy in die lewensaand op die reeds volbragte dagtaak kan terugkyk, ontbreek dit hom aan voldoende dryfkrag.

Die liggaamlike verswakking werk ook remmend ij op die wilsuitinge in die ouderdom. Vermoeidheid, motoriese stramheid en die vertraging van sy reaksievermoë, beĭnvloed die oumens se wilslewe op negatiewe wyse.

Die vermindering van die psigiese energie met die daarmee gepaardgaande daling van lewenslus veroorsaak geestelike vermoeidheid en bedruktheid. Dit bemoeilik wilsuitinge op die subjektiewe vlak.

Die gewoonte wat deur die jare heen aangeleer is, het sy voordeel sowel as sy nadeel m.b.t. die wilslewe in hoë ouderdom. Die voordeel is dat 'n bepaalde manier van doen wat aanpas by die persoon se persoonlikheid, op outomatiese wyse in die ouderdom uitgevoer word.

Die nadeel hieraan verbonde is dat handelswyses wat so deur die gewoonte geoutomatiseer is, botsend is en verwarrend werk in heeltemal nuwe situasies, in die neem van besluite en die oplossing van probleme wat verskil van die in die gryse verlede. Dit bring probleme mee wat die mode betref, die fatsoen, opvattings oor manierlikheid, taalgebruik, die verhouding tussen die geslagte ens. 


\section{E. BENADERING EN HANTERING VAN DIE BEJAARDE}

Dit is onmoontlik en ook onlogies om onbuigbare reëls te gaa neerlê vir die benadering en hantering van die bejaarde. Elke oumens is natuurlik 'n persoon op homself, met sy eie aard, sy eie geskiedenis en eie persoonlikheid. Gevolglik sal elkeen goed geken moet word en dan op sy eie meriete behandel word. Tog sal dit moontlik wees om in die lig van die fisiologiese- en psigologiese aspekte van die ouderdom 'n paar hoofriglyne aan te stip.

Uit die voorgaande bespreking blyk dit dat die psigologiese behoeftes van die bejaarde veral die volgende is:

1. Eensaamheid, geestelik sowel as sosiaal.

2. Minderwaardigheidsgevoelens as gevolg van liggaamlike onvermoë en die sosiale verskuiwing van sy eertydse status en rol.

3. Angs, voortvloeiende uit die eensaamheid en die minderwaardigheidsgevoelens.

4. Bedrukte stemmings op grond van sy lewensliefde aan die eenkant en die beperktheid van die lewe aan die anderkant.

5. Heimweë na die dinge wat onherroeplik verby is.

6. Skuldgevoelens, wat godsdienstig van aard is.

Met die oog op die bestaande behoeftes is dit baie duidelik dat die oue van dae in die eerste plek met baie liefde en respek benader moet word. 'n Vriendelike begroeting, 'n glimlag, 'n sagte woord en 'n gemoedelike omgang, sal bydra tot die kleur wat die lewe vir die bejaarde gaan aanneem.

Dog die liefde moet met begrip gegee word, anders sal dit niks baat nie. Die bejaarde moet so met die liefde omring en daardeur gedra word dat dit sy selfgevoel inderdaad sal versterk, sy eensaamheid verlig en sy gevoel van minderwaardig. heid laat verdwyn. Derhalwe moet die liefde nie oordoen word sodat dit eintlik verword tot 'n pap-sentimentele vertedering nie. Dit aksentueer die fisiese en psigiese agteruitgang nog meer vir die bejaarde. Dikwels word met oumense gepraat soos met klein kindertjies. Hulle word aangespreek met allerhande troetelname soos „oupatjie” en „oumatjie”, of selfs „oudjie”. Hoewel hierdie aanspreekvorms baie goed bedoel word, het dit tog nie die gewenste uitwerking nie. Dit is maklik te verstaan as in 
gedagte gehou word dat elke bejaarde deur die jare heen gewoond was daaraan om aangespreek te word as "meneer" of „,mevrou”, of as „oom so" en „tante dit". Dit krenk sy waardigheid as hy nou in ny ouderdom met 'n verkleinwoordjie aangedui word. Daardeur word hy gederpsonifiëer tot 'n ,,iets", terwyl hy graag die persoon wil bly wat hy altyd was. Die aangewese weg sou wees om elke bejaarde op die naam te noem waarmee hy nog altyd deur die lewe gegaan het.

Ten einde in al die psigologiese behoeftes van bejaardheid te voorsien, sal dit 'n stap in die regte rigting wees om aan die volgende oorwegings aandag te skenk:

(i) Die bejaardes moet dikwels sosiale besoeke ontvang by hulle huise, of in hulle kamers in ouetehuise.

(ii) Daar moet gereeld onder leiding van 'n sielkundige groepsbesprekings met die bejaardes gehou word. Dit sal terapeutiese voordele meebring en die aanpassing van die bejaardes verbeter. Gedurende die groepsbesprekings sal hulle behoeftes ook aan die lig kom wat andersins miskien nooit deur hulle genoem sou gewees het nie. Tydens die groepsbesprekings kan die sielkundige die bejaardes leer ken op 'n onopsigtelike wyse, hulle sielkundige probleme ontdek, vasstel tot watter tipe elkeen behoort en die ouetehuispersoneel dan voorlig hoe om veral die probleemgevalle te hanteer.

(iii) 'n Vaste ouetehuis-predikant is 'n noodsaaklikheid met die oog op gereelde, gesistematiseerde en sinvolle pastorale bearbeiding van hulle wat die lewensaand bereik het. Hoewel dit waar is dat oumense meer religieus is in hulle ouderdom, kan hulle ook verval tot onverskilligheid en ongeloof. Tereg sê Kimball Young (1952, p. 585) : „However, individuals who had once been religious but had lost their faith in it tended to show poor adjustment". Die byna wanhopige klag van Gilhuis (a.w. p. 179) is nie alleen 'n beskuldiging nie, maar ook 'n kragdadige aansporing wanneer hy sê : „Is er een hele methodisch-verantwoorde benadering van de jeugd - de ,massa' - en de georganiseerde jeugd - gegroeid, geeft men hiervoor handleidingen en bladen uit, roept men deze jeugd in clubhuizen en lokalen bij elkaar - wat de bejaarden betreft, is men nog niet eens aan een bezinning op een juist benadering van hun problemen toegekomen. Dit alles tot schade van de bloei van dit werk en 
van het heil der betrokken zielen, die voor de deur der eeuwigheid staan in een bijna geëindig ,heden der genade'."

Oor die wyse waarop elk van bogenoemde drie punte uitvoering gebring moet word, sal in ' $n$ ander referaat gehandel moet word.

\section{GERAADPLEEGDE WERKE :}

1) Gilhuis, C. (1956), Pastorale Zorg aan Bejaarden, Kok, Kampen.

$\Rightarrow$ Young, Kimball (1952), Personality and Problems of Adjustment. Routledge \& Kegan Paul, London.

3) Bejaardenwerk, Praktisch Teologische Handboekjes, (1958), Boekencentrum, 'S-Gravenhage.

t) Harriman, P. L. (1947), The New Dictionary of Psychology, Philosophical Library, New York. 